\title{
Dizer a violência
}

\author{
Naming Violence
}

Este número de Katálysis é inteiramente dedicado ao tema das violências. Violências assim, no plural, pois que não existe 'a' violência, mas muitas, diversas, postas em distintas funções, servindo a diferentes destinos. É exatamente a polissemia da 'violência' que a torna plural e que exige muita precaução teórica, se não quisermos deixar nossa análise deslizar para dentro da 'violência'.

O primeiro cuidado que tomamos é reconhecer que ao dizermos de algo que ele é violento nós não estamos apenas descrevendo um evento, mas intervindo nele. Dizer que alguém é violento é agir sobre essa pessoa, é demandar algo como uma outra violência para interromper a violência dessa pessoa. Disse 'algo como uma outra violência' também por precaução, pois aprendemos que poder e violência são aparentados, mas diferentes. Para Max Weber, ambos os termos são amorfos, aplicam-se a qualquer possibilidade de um indivíduo ou grupo impor sua vontade sobre outros, mesmo contra a resistência desses. A diferença fica por conta do emprego ou não da força física para obter o resultado pretendido e, portanto, no limite, da maior ou menor legitimidade que a imposição da vontade obtenha da obediência. É também nessa direção, mas de uma perspectiva mais liberal, que Hannah Arendt distingue o poder da violência, contra a tradição marxista mais radical que não via razões para distinguir os dois conceitos: "o poder está na ponta do fuzil", dizia o jovem Mao, secundado por Franz Fannon.

Outro cuidado necessário é reconhecer que estamos tratando de conflitos e não apenas de normas sociais. A dimensão social da violência poderia ser descrita como um paradoxo: numa ponta surge o conflito, na outra o seu extermínio. Assim, a violência é uma forma de produzir e conduzir conflitos e também uma forma de acabar com o conflito, de exterminá-lo. Para pensadores como Foucault, Deleuze, Derrida, por exemplo, a violência não está no conflito, mas em - tendo já obtido a rendição do Outro - continuar uma luta já sem a resistência da outra parte, violentá-lo, exterminá-lo. A violência não estaria no conflito, mas na inexistência do conflito.

Sem dúvida que as violências são sempre designadas em contextos normativos e jamais fora deles. Nesse sentido, não é dispensável lembrar que toda singularidade de um evento não desperdiça seus referenciais de significado, que estão e, ao mesmo tempo, não estão no acontecimento específico. Uma parte do significado é amplamente partilhada para além daquele evento, numa dimensão mais estruturada da formação social. Na tradição marxista, poderia ser confundida com a ideologia dominante ou, mais sofisticadamente, com a hegemonia. Na tradição weberiana, com racionalizações próprias a uma esfera de sentido. $\mathrm{Na}$ escola durkheimiana, é a lei quem cria a violência, é a reação moral quem designa o desvio e o crime, e não o contrário. A lei não nasce para conter a transgressão, isso seria um contra-senso, já que o que define a transgressão é a existência da lei. A lei (ou a estrutura, se preferirem) é anterior à singularidade que será designada desviante, o desvio é efeito da lei (ou da estrutura, como querem muitos). Na tradição psicanalítica, é também a lei quem delimita o registro do perverso e do patológico.

Tudo isso para evitar dizer a violência: analisamos o que é dito violento, trazendo o conflito recalcado à tona, mas evitamos nós mesmos dizer a violência se quisermos obter uma boa análise. Só devemos dizer a violência quando deixamos esse lugar da ciência e assumimos nossa participação no conflito, como cidadãos. Na prática, muitas vezes misturamos os dois lugares num mesmo discurso, mas um não ajuda ao outro, servem a funções diferentes. Não conheço melhor a violência, dizendo-a, mas evitando dizê-la.

Como operar analiticamente com a palavra 'violência' após todas essas considerações? Se bem en- 
tendida a argumentação que nos trouxe até aqui, 'violência' não pode ser um conceito, no máximo pode ficar no registro descritivo do tipo "uso da força física e de suas extensões tecnológicas para impor uma ação (ou omissão) a outrem'. Mas mesmo isso não seria suficiente, já que há usos para designar agressões não físicas, mas morais - a 'violência verbal', por exemplo, que pode produzir, em alguns casos, efeitos moralmente mais devastadores que a agressão física, como Goffman demonstrou em seu estudo sobre o Estigma. As passagens de significado seguem o curso da maior ou menor valorização da 'pacificação' das relações sociais, como preferiria a perspectiva de Norbert Elias. Para essa perspectiva, a violência é pré-civilizatória e o processo civilizatório é definido exatamente pela sua capacidade em alijar a violência das relações sociais, ritualizando o controle social no cotidiano e deixando ao Estado, detentor monopólico do emprego da força física, o direito exclusivo de dizer a violência.

Como tratar de todas essas questões em nossas pesquisas no Brasil? É preciso primeiro constatar que vivemos pela primeira vez em nossa história uma experiência de democracia de massa. Uma democracia incompleta, repleta de contradições, mas que vem se afirmando contra o anterior solo pantanoso das crenças hierárquicas e discriminatórias. À normalização do individualismo que retoma o seu curso no Brasil, junta-se um processo desnormalizador baseado no tradicional individualismo hierárquico de nossa formação histórica, por um lado, e na dissolução dos vínculos sociais e da estabilidade do emprego e da profissão produzida pelo capitalismo tardio, por outro lado. A expansão da informalidade e dos mercados ilegais, o lusco-fusco do lícito e do ilícito no cotidiano da economia, da política e dos costumes, todo esse processo social associa-se a uma acumulação social da violência como percurso histórico que teria decorrido da 'ausência do Estado' em cumprir suas atribuições, entre as quais a de deter o monopólio do emprego legítimo da violência em todo o seu território. Esquece-se, astuciosamente, no entanto, que o processo civilizatório elisiano não depende apenas da capacidade dissuasória do Estado, mas também da economia de repressão representada pela internalização do autocontrole nos comportamentos, um processo que depende de compensações sociais que tornem o auto-controlar-se desejável e racionalmente preferido. A medida do escândalo e da vergonha não é dada pelo Estado, mas pela sociedade.

No Brasil, os índices de crimes violentos em capitais como o Rio de Janeiro e São Paulo começaram a apresentar aumento a partir de meados da década de 1970, sem apresentar qualquer recuo em três décadas. O sentimento de insegurança exponenciou-se no mesmo período, potencializado por uma mídia sedenta de público e de espetáculo. Em conseqüência, o tema da 'violência urbana' passou a freqüentar os noticiários e os debates públicos, alçando-se, a partir dos anos 90, em uma das principais preocupações do cidadão, ao lado do emprego e da saúde. Inicialmente confinado aos crimes convencionais - roubo, tráfico, estelionato - o tema ganhou qualificação sociológica e jurídica com as violências 'especializadas': de gênero, na escola, doméstica, no futebol etc. A introdução de novas qualificações da violência acompanhou uma extraordinária demanda de punibilidade e justiça, que fez a população penitenciária do país passar de 30 por 100 mil habitantes em 1969 para 215 por 100 mil habitantes em 2006. No entanto, reclama-se cada vez mais da baixa capacidade punitiva da justiça brasileira, o que serviria de justificação, em alguns segmentos da população e da polícia, para soluções extralegais, como o justiçamento e extermínio de suspeitos de crimes nas periferias das grandes cidades. No Brasil, há inacreditáveis 50 mil vítimas de homicídio intencional, todo ano, a esmagadora maioria por arma de fogo, números que superam os de quase todas as guerras conhecidas da segunda metade do século 20. Mas será essa a principal violência existente na sociedade brasileira? Como no poema de Brecht, olhamos as águas torrenciais e violentas do rio caudaloso que desce rompendo com suas margens estreitas, mas esquecemos da violência de suas margens, que aprisionam seu leito, obrigando-o ao ímpeto destruidor.

Os artigos que compõem esta edição de Katálysis buscam lidar com dilemas como esses que apontamos, os problemas teóricos e empíricos que se colocam para o pesquisador dessa área temática. Contribuem na sua diversidade de abordagens e objetos, para uma melhor compreensão da complexidade envolvida no tema das violências e do quanto a ampliação semântica do campo resulta da ampliação do dizer a violência na sociedade e no Estado: se as análises de Elias estiverem certas, indicam também uma ampliação da demanda civilizatória entre nós.

\section{Michel Misse}

Doutor em Sociologia pelo Instituto Universitário de Pesquisas do Rio de Janeiro (IUPERJ) e pela École des Hautes Études en Sciences Sociales (EHESS)

Professor de Sociologia do Departamento de Sociologia e do Programa de Pós-Graduação em Sociologia e Antropologia da Universidade Federal do Rio de Janeiro (UFRJ)

Coordenador do Núcleo de Estudos da Cidadania, Conflito e Violência Urbana (NECVU) da UFRJ

Pesquisador do CNPq 